\title{
La dictadura, las formas de la represión y los estudios a escala local
}

\author{
Dictatorship, modes of repression and local studies
}

\author{
Gabriela Águila \\ gbaguila@gmail.com \\ Investigaciones Socio Históricas Regionales (ISHIR) \\ - CONICET / Universidad Nacional de Rosario, \\ Argentina
}

Cita sugerida: Águila, G. (2021). La dictadura, las formas de la represión y los estudios a escala local. Anuario del Instituto de Historia Argentina, 21(1), e134. https://doi.org/10.24215/2314257Xe134
Resumen: En sintonía con una tendencia muy visible en la renovación de la historiografía argentina de las últimas décadas, el desarrollo de la historia reciente como campo de estudios debe mucho al cambio de escala y a los abordajes centrados en lo local. Esto se ha verificado, entre otros temas y procesos, en las investigaciones sobre la última dictadura militar y sobre la violencia estatal y paraestatal. La preeminencia de miradas "macro" sobre el régimen militar y el dispar conocimiento sobre las dinámicas locales y regionales de la represión alentaron el desarrollo de indagaciones que optaron por achicar el foco del análisis hacia lo local, visibilizando actores, tramas sociales y lógicas políticas poco analizadas, iluminando en su singularidad modalidades, prácticas y efectos de la represión y poniendo en debate cronologías y formas canónicas de interpretar aquellos procesos históricos. Con el objetivo de dar cuenta de estos desarrollos y relevar sus aportes, este artículo pone el foco en el funcionamiento del régimen militar en el nivel municipal y los comportamientos sociales y, por otro lado, en el ejercicio de la represión a escala local, analizando también los archivos y las fuentes para el estudio de estas problemáticas.

Palabras clave: Dictadura, Represión, Estudios locales.

Abstract: According to a main trend in the renewal of Argentine historiography in the last decades, the development of recent history as a field of study owes much to the change in scale and local-centered approaches. This has been verified, among other issues and processes, in the investigations about the last military dictatorship and state and parastatal violence. The preeminence of "macro" views on the military regime and the dissimilar knowledge about the local and regional dynamics of the repression led to the development of research that focused on local perspectives, making visible actors, social plots and political process, illuminating in their singularity modalities, practices and effects of repression and putting in debate chronologies and canonical ways of interpreting those historical processes. In order to account for these developments and highlight their contributions, this article focuses on the functioning of the military regime at the municipal level and social behaviors and, on the other hand, on the exercise of repression at the local scale, analyzing also the archives and sources for the study of these problems.

Keywords: Dictatorship, Repression, Local studies. 
Los estudios sobre la última dictadura militar (1976-1983) y, más en general, el campo de la Historia reciente argentina, estuvieron fuertemente influenciados por interpretaciones de tipo macro-analíticas sobre todo las provenientes de la sociología o la ciencia política, pero también de los estudios sobre la memoria- a la vez que por el predominio de una mirada "nacional" o, más bien, de abordajes generalizadores centrados en la realidad capitalina o bonaerense que, en general, soslayaban lo acaecido en otros espacios provinciales, locales o regionales (Águila, 2008; Jensen, 2010; Bohoslavsky y Lvovich, 2017). A medida que se multiplicaban las investigaciones y la historia reciente se consolidaba como campo de estudios, el problema de las escalas de análisis concitó la atención de los especialistas, aunque con algún rezago comparado con la centralidad de otros temas -tales como las relaciones entre historia y memoria, las temporalidades y los límites de "lo reciente", el estatuto de las fuentes orales y escritas o el lugar de las y los historiadores del presente (Pittaluga, 2017; Franco y Lvovich, 2017)-.

Eso respondía, en gran parte, a la escasez de conocimientos sobre el pasado reciente en general y sobre la última dictadura en particular, y a los importantes vacíos que se registraban en la investigación sobre espacios extra-capitalinos, locales, provinciales o regionales. Asimismo, el cuestionamiento a la preeminencia de perspectivas "macro" o "porteño-céntricas" no era ajeno a una tendencia muy acusada en la renovación de la historiografía argentina y latinoamericana: el desarrollo de abordajes a escala local y regional (o sub-nacional), de fuerte presencia en muchos ámbitos universitarios y centros de investigación del país, también en donde se formaban e investigaban especialistas en la historia reciente. Resultado de ello fueron los numerosos trabajos y líneas de indagación sobre temas muy diversos, basados en análisis situados en específicos espacios provinciales, locales o regionales, que han contribuido a complejizar el conocimiento y las interpretaciones sobre procesos socio-históricos acaecidos en el pasado reciente, desarrollos que discurrieron a la par de la reflexión y el debate sobre el problema de los niveles y escalas de análisis y observación.

Como sostienen Jensen y Lastra, siguiendo a Revel (2015), ninguna escala es neutra ni está definida de antemano, sino que constituye una elección de las y los investigadores, vinculada con sus preguntas, su objeto de estudio, las dimensiones que pretende indagar, las fuentes con las que cuenta, etc. En tal sentido, la escala es una opción metodológica (Pons y Serna, 2007), ${ }^{1}$ y como tal fue asumida de modos más o menos reflexivos por especialistas en el estudio del pasado reciente, además de estar frecuentemente determinada por la disponibilidad y/o el mayor acceso a reservorios documentales provinciales o locales, en general inexplorados para estos períodos y problemas. Con todo y las limitaciones que se verifican en términos de la ausencia de una política nacional de archivos, las restricciones al acceso o las enormes diferencias existentes en las distintas provincias y ciudades, es un dato cierto que en los últimos años se han acrecentado los archivos y fondos públicos o privados disponibles para la investigación sobre el pasado reciente, producidos por diversas agencias estatales provinciales o municipales, así como "archivos de la represión", archivos de la memoria, fondos documentales de organizaciones intermedias o movimientos sociales, colecciones hemerográficas digitalizadas, entre otros, que han favorecido la realización de estudios que contemplen una reducción de la escala de observación y análisis.

Como hemos afirmado, los abordajes desde lo local han tenido un fuerte impacto en las investigaciones sobre la última dictadura militar y el ejercicio de la represión estatal y paraestatal (en una temporalidad un poco más amplia, que desborda el período 1976-1983). El dispar conocimiento disponible sobre las lógicas de actuación del régimen militar a nivel provincial y municipal, sobre actores y movimientos sociales y políticos que mostraban variaciones en su actuación en distintos escenarios y sobre el despliegue de la violencia estatal a escala provincial, regional y local, alentaron el desarrollo de investigaciones individuales y proyectos colectivos 
que, entre otras derivas, optaron por achicar el foco del análisis, visibilizando actores, tramas sociales y lógicas políticas del régimen militar poco analizadas, iluminando en su singularidad modalidades, prácticas, circuitos y efectos de la represión estatal y paraestatal y poniendo en tensión cronologías y formas canónicas de interpretar aquellos procesos históricos.

El objetivo de este artículo es dar cuenta de algunos de esos desarrollos investigativos, así como de los aportes provistos por los abordajes a escala local en el campo de los estudios sobre la dictadura y la represión en la historia reciente argentina. Para ello se pondrá el foco en algunas cuestiones que concentraron la atención de las y los investigadores del período: el funcionamiento del régimen militar en el nivel municipal, la "micropolítica" de la dictadura y los comportamientos sociales y, por otro lado, el ejercicio de la represión a escala local, finalizando con algunas reflexiones sobre los archivos y las fuentes para el estudio de estas problemáticas.

\section{EL RÉGIMEN MILITAR A ESCALA LOCAL, LOS CONSENSOS Y LAS RESISTENCIAS}

Como ha sucedido en los estudios sobre las dictaduras del Cono Sur, en particular la chilena y la uruguaya (Valdivia Ortiz de Zárate et al., 2012; Demasi, 2013; Correa Morales, 2016), también en el caso argentino se viene insistiendo en la importancia que ostentó el espacio municipal para las dictaduras militares instaladas en los años '60 y '70. Con diferencias más o menos señaladas, el ámbito de los municipios adquirió centralidad para estos regímenes, en un contexto donde las formas tradicionales de representación ciudadana (especialmente, los partidos políticos) habían sido prohibidas o cercenadas en su funcionamiento y se propugnó la participación a través de "cuerpos intermedios" (Galván y Osuna, 2014; Di Giorgi, 2014-2015).

En lo que refiere a la última dictadura, contamos con algunas indagaciones que han puesto el foco en el nivel municipal, tal el caso de la socióloga Paula Canelo, quien ha afirmado que el municipio fue un eslabón fundamental para el régimen militar, analizando en profundidad los planes políticos de la dictadura y el reclutamiento de funcionarios en distintos niveles del estado, entre ellos en el municipal (Canelo, 2015). Desde perspectivas más o menos afines, historiadores y otros cientistas sociales elaboraron estudios situados en algunas provincias (Buenos Aires, Santa Fe, Córdoba) y en ciudades de distinto rango (grandes urbes como la Capital Federal, Rosario, Córdoba o Mar del Plata, ciudades de tamaño mediano como Bahía Blanca, Santa Fe y Rafaela, y localidades más pequeñas como Morón, General Sarmiento o Lincoln). ${ }^{2}$ Estos trabajos han analizado aspectos tales como las estrategias de legitimación del poder municipal, las vinculaciones con instituciones y organizaciones de la sociedad civil, la "micropolítica" de la dictadura a escala local, el reclutamiento de funcionarios y, en menor medida, la actuación de algunos actores, corporaciones o asociaciones. Mientras que algunos han puesto de relieve el apoyo o la complicidad civil con las autoridades militares (el papel de los medios de comunicación locales, por ejemplo, ocupó gran parte de la atención), otros han explorado los comportamientos y actitudes sociales, poniendo en debate las explicaciones disponibles sobre las relaciones entre dictadura y sociedad. Aun sin omitir que no contamos con investigaciones para todas las provincias y menos aún para un conjunto más o menos representativo de ciudades localizadas en un territorio tan vasto, heterogéneo y complejo como el argentino, dichos abordajes permiten un acercamiento al problema del ejercicio del poder a escala local durante la última dictadura, que examinaremos en forma panorámica.

La organización del régimen militar instalado el 24 de marzo de 1976 fue cuidadosamente establecida en los documentos básicos del Proceso de Reorganización Nacional (PRN). Se trataba de una estructura piramidal en cuyo vértice se ubicaba la Junta Militar, el "órgano supremo de conducción” y un esquema de poder compartido con representación de las tres armas, tanto en la Junta Militar y el gabinete como en otros ámbitos del estado (los gobiernos provinciales y municipales, los organismos y empresas estatales), si bien el Ejército tuvo primacía. 
En el momento del golpe de estado se designaron interventores militares en todas las provincias, quienes fueron reemplazados entre abril y mayo por gobernadores escogidos por la Junta Militar (una de las excepciones fue la provincia de Tucumán, que permaneció a cargo del comandante militar, general Antonio Domingo Bussi, primero interventor y después nominado gobernador hasta diciembre de 1977), altos oficiales retirados de las distintas fuerzas casi en su totalidad, si bien también hubo una mayoría del Ejército, que controló la mitad de las veintidós provincias (Quiroga, 1994; Canelo, 2011). Según se consignó en distintos medios, los nombramientos fueron precedidos de "exhaustivas consultas" y de "largas conversaciones" con los destinatarios, para imponerlos sobre los lineamientos del PRN. Como expresión del alto grado de militarización del estado, se trató de un elenco gubernamental integrado mayoritariamente por militares, aunque contó con algunos civiles en puestos importantes, señaladamente en los ministerios de Economía y Educación. Por su parte, los gobernadores militares organizaron sus respectivos gabinetes incorporando a algunos civiles, con variaciones según cada provincia, mientras que fue en los ámbitos municipales y/o comunales donde se verificó la mayor presencia de civiles en los puestos de gobierno.

A diferencia de lo sucedido en la anterior dictadura (1966-1973), los militares no prohibieron la actividad político-partidaria, pero le impusieron importantes restricciones. Por el decreto $n^{\circ} 6$ (mayo de 1976) se dispuso la suspensión de la actividad de los partidos políticos y en junio se dictaron cuatro leyes por las que se disolvían y/o declaraban ilegales varias decenas de agrupaciones políticas, sindicales y estudiantiles, casi todas ellas ligadas a la izquierda peronista y marxista. Además, se permitió la supervivencia de algunos espacios para que las organizaciones que no fueron ilegalizadas (los considerados partidos "parlamentarios") pudieran seguir funcionando, aunque con importantes limitaciones. Así, la actividad política permaneció suspendida pero no prohibida, lo que equivalía a aceptarla en forma limitada y, como ha planteado Yannuzzi (1996: 73), el régimen militar recurrió a los partidos con dos objetivos: como embajadores, para obtener legitimidad a nivel internacional y para cubrir cargos en el nivel municipal (como intendentes o presidentes de comuna).

Tal como sucedió en el nivel provincial, en los grandes centros urbanos se designaron interventores o delegados militares en el momento del golpe (casi todos oficiales de rango medio del Ejército) y un mes después fueron reemplazados por intendentes del mismo origen, altos oficiales en general retirados del servicio activo. Aunque no tan claramente como en otros ámbitos del poder estatal, se mantuvo el reparto tripartito del poder entre las tres armas: por ejemplo, la Municipalidad de la Ciudad de Buenos Aires quedó en manos de la Fuerza Aérea (brigadier Osvaldo Cacciatore), Rosario y Mar del Plata a cargo de la Armada (capitanes de navío Augusto Félix Cristiani y Carlos Menozzi, respectivamente), Córdoba y Tucumán (coronel Héctor Romanutti y general Antonio Domingo Bussi), para el Ejército. Sin embargo, en la mayor parte de las pequeñas ciudades y comunas fueron los civiles los que constituyeron el elenco gobernante de la dictadura.

Según un informe de la Secretaría de Informaciones del Estado publicado en marzo de 1979 (citado en Lvovich, 2010: 416), solo el 10\% de los municipios (1.697 en todo el país) tenía intendentes militares. Esto mostraba una diferencia significativa con el nivel provincial donde los gobernadores militares fueron una abrumadora mayoría frente los civiles: más del 75\% del total entre 1976 y 1983 y mayoría absoluta hasta 1981 (Canelo, 2015: 409). De ese total de intendentes civiles, un 38\% no poseía militancia política, mientras que el 52\% restante provenían de los partidos tradicionales: la Unión Cívica Radical (310), Partido Justicialista y otros afines (192), Partido Demócrata Progresista (109), Movimiento de Integración y Desarrollo (94), Fuerza Federalista Popular (78), Partido Demócrata Cristiano (6) y Partido Intransigente (4) (Lvovich, 2010: 416). Como se advierte, y aunque en una muy alta proporción se trataba de hombres "sin militancia política" (aunque seguramente integraban las "fuerzas vivas" de la localidad), la mayoría estaban filiados en distintas organizaciones políticas, tanto los partidos "amigos del Proceso" (organizaciones o alianzas de centro-derecha encolumnadas con el régimen militar, como el Movimiento de Integración y Desarrollo, Fuerza Federalista Popular, el Movimiento Línea Popular o el Partido Demócrata Progresista), como los dos grandes partidos nacionales, el radicalismo y el peronismo. 
Algunos de los que encabezaron los gobiernos municipales venían desempeñándose en esos puestos y/o habían sido electos hacia 1973, marcando en esos espacios políticos locales una línea de continuidad con el período democrático precedente. Asimismo, sea que las cabezas del ejecutivo municipal fueran militares o civiles, frecuentemente sumaron a otros civiles en sus gabinetes como funcionarios o en calidad de asesores, como sucedió en Rosario, en la capital cordobesa, en muchas ciudades de la provincia de Buenos Aires y de otras provincias del país. Se trataba, frecuentemente, de "personalidades" relevantes de la escena local o miembros de los "sectores representativos", a los que el régimen militar convocó como interlocutores y apoyo, por fuera de identificaciones o pertenencias político-partidarias.

En los primeros años, las convocatorias realizadas por el régimen militar no tuvieron como destinatarios a los partidos políticos, sino que se orientaron -como hizo Videla en el discurso de cierre de la reunión de gobernadores en julio de 1976- a los "ciudadanos capaces, experimentados y representativos", solicitando "la colaboración y el consejo", pero evitando la política partidista en tanto "sectarización del poder"(Clarín, 1/7/76). Dirigidas hacia "los argentinos de buena voluntad", se plasmaron en contactos con "personalidades destacadas" que realizaron algunos jerarcas del régimen (son recordados los almuerzos que compartió Videla con científicos, políticos y escritores renombrados en mayo de 1976), en las instrucciones del ministerio del Interior a los gobernadores para la designación de intendentes "sobre la base de la idoneidad, representatividad y honestidad" (El Litoral, 3/6/76), en los contactos con los sectores "representativos de la comunidad" en espacios provinciales y locales y, también, en el llamamiento al "diálogo político" organizado por el ministro del Interior Albano Harguindeguy en 1980-1981. Junto con registrar las apelaciones del régimen hacia los civiles, así como la importante presencia que estos tuvieron en distintos niveles del estado, interesa señalar que -aunque en muchos casos se trataba de hombres filiados en los partidos políticos y con militancia más o menos reconocida- las convocatorias y la participación civil en los elencos del régimen se presentaron de forma despolitizada. Lo que estaba ausente entonces no era la política o los políticos, sino los partidos como instancias de representación ciudadana y canal de intermediación entre la sociedad y el estado.

En este punto, podría realizarse una distinción entre las grandes ciudades, que fueron gobernadas brevemente por interventores (o delegados de la Junta Militar) y luego por intendentes militares designados, y las pequeñas ciudades y comunas, que quedaron en manos de civiles. Las capitales de provincias y los grandes centros urbanos ubicados sobre todo en el centro del país mostraron el alto grado de militarización del estado y el reparto tripartito del poder que caracterizó al régimen instalado en 1976, también en el nivel municipal. Estos oficiales de las distintas fuerzas, designados como intendentes, eran en su mayoría recién llegados "desde fuera" del ámbito local -aunque también hubo otros que conocían la provincia, como el coronel Romanutti, quien había sido jefe de la Policía de Córdoba entre 1969 y 1970 e intendente de facto de Jesús María entre 1972 y 1973 (Herrero, 2020)- y debieron darse a la tarea de establecer vínculos con los sectores "representativos" de la comunidad, interactuar con corporaciones, instituciones y asociaciones locales, así como eventualmente recibir sus demandas. Como se verificó para el caso de la ciudad de Rosario durante la intendencia del capitán Cristiani (Águila, 2014), sea en la prensa de la época, como en las declaraciones de altos oficiales e incluso en entrevistas realizadas a funcionarios municipales, se encuentran referencias a las consultas realizadas entre sectores "representativos" de la comunidad para la selección de los intendentes, así como la incorporación en los gabinetes municipales de hombres provenientes de diversos espacios del quehacer local, que se sumaron bien como "asesores civiles", bien como funcionarios con activa participación en la gestión gubernamental.

Por su parte, quienes han indagado en ciertos espacios locales, ciudades pequeñas o pueblos a lo largo y ancho del país, frecuentemente han planteado que las memorias locales no registran grandes variaciones debidas al golpe de estado de 1976, poniendo en cuestión la idea de corte abrupto con el período previo que la dictadura significó en la historia nacional. Esto puede deberse a diversas cuestiones, entre ellas a los modos en los que se configuran las memorias, pero la idea de que en tal o cual localidad "no pasó nada" en los años dictatoriales es atribuible por sobre todo a un menor impacto o alcance de la represión y las medidas de 
control social implementadas por el régimen militar, pero también a la escasa variación en los climas políticos y sociales en una escala "micro", por ejemplo, la permanencia del intendente o el presidente de comuna más allá de los cambios a nivel nacional o que las tramas de poder local se hayan mantenido incólumes.

La presencia de civiles se amplificó a partir de 1981, durante la presidencia del general Roberto Eduardo Viola. En un intento de tibia apertura, que contemplaba la convocatoria al diálogo y el acercamiento a los partidos políticos, anunció que aumentaría la "participación civil" incluyendo gobernaciones de provincia y ministerios. En los primeros meses de 1981 la Junta Militar designó gobernadores e intendentes civiles en casi todas las jurisdicciones del país, en su mayoría vinculados a partidos "amigos del Proceso", muchos de los cuales tenían experiencia y trayectoria política. Y aunque esta estrategia se topó rápidamente con la oposición de los sectores más duros de las Fuerzas Armadas -resolviéndose con el alejamiento de Viola y la asunción como presidente del general Galtieri en diciembre de 1981 - en los años siguientes, se continuó con los nombramientos de civiles en gobernaciones e intendencias.

Más allá de la estructuración del régimen militar y de los cambios que se produjeron en sus distintas fases respecto de la participación de los civiles en los elencos de gobierno, fue en el espacio municipal donde la interacción entre civiles y militares (o, si se quiere, el carácter cívico-militar del régimen) se mostró con mayor amplitud. En los espacios restringidos de ejercicio de la política que subsistieron en sus primeros años, el régimen militar otorgó particular atención al ámbito municipal, en la búsqueda de ampliar sus bases de sustentación, tanto en el reclutamiento de funcionarios como en las relaciones establecidas con instituciones, corporaciones y organizaciones intermedias que actuaban a escala local. El ejercicio de la política en esos espacios locales -considerado "legítimo" y autorizado por el régimen militar-, tuvo algunas características diferenciadas de la "alta política" que se realizaba en el ámbito capitalino. En las ciudades grandes y pequeñas de las distintas provincias del país, los representantes del régimen (fueran estos militares o civiles), interactuaban con sectores de la sociedad civil, nucleados en las denominadas "fuerzas vivas", las que oficiaron como sostén de la dictadura a escala local. Se trataba de sectores más o menos organizados y con capacidad de reclamo e intervención pública, que incluían a las corporaciones empresarias (rurales, urbanas, de grandes o pequeñas empresas, de comerciantes), organizaciones intermedias (colegios profesionales, asociaciones étnicas, culturales, sociales o clubes deportivos), sectores influyentes en el ámbito local, como los medios de prensa, las iglesias (en particular la Católica) y las ligas y asociaciones religiosas, y también los vecinos agrupados en sus asociaciones barriales o vecinales, muchas veces de orígenes y ubicación urbana más humilde. En el juego de la "micropolítica" local, la iniciativa estuvo en general del lado del régimen, si bien estos sectores -que además estaban representados por algunos de sus hombres en los elencos gubernamentales- mostraron iniciativa y capacidad de presión para imponer algunas de sus demandas a lo largo de toda la dictadura y, en algunos contextos, cuestionaron abiertamente las políticas implementadas.

A la vez que se ha señalado "la importancia alcanzada por el nivel municipal como locus de ejercicio de la política” (Canelo, 2015), los municipios han sido un ámbito privilegiado para explorar las relaciones entre régimen y sociedad, el despliegue de estrategias hacia la sociedad civil y los comportamientos y actitudes sociales (Lvovich, 2010), que incluyeron expresiones de apoyo activo, de conformidad o acatamiento pasivo a las convocatorias del poder militar, así como el disconformismo, las resistencias y críticas que se expresaron de modos diversos en los siete años que duró la dictadura. El análisis de las resistencias a la dictadura y sus expresiones a escala local requeriría un pormenorizado estudio, que está por fuera de las posibilidades de este texto, por lo que solo mencionaré algunas cuestiones referidas a los actores y movimientos en los que se ha focalizado la investigación.

Para empezar, los estudios disponibles sobre los trabajadores y la conflictividad laboral en dictadura han tenido un sustancial avance en estos últimos años, se han revisado interpretaciones muy extendidas (como la de la "inmovilidad" de la clase obrera en el período), y se han sumado estudios centrados en el análisis de casos, de ramas o empresas ubicadas en determinadas regiones o espacios locales específicos, mostrando el 
dinamismo de la historia local/regional, facilitada además por el acceso a nuevas fuentes y archivos (Schneider y Simonassi, 2019).

Lo mismo podría decirse de los estudios sobre el movimiento de derechos humanos, fuertemente influenciados por un relato "canónico" sobre el surgimiento y desarrollo de los organismos en la zona metropolitana Buenos Aires-La Plata, que ha sido puesto en cuestión por el avance de las investigaciones sobre otros espacios de la Argentina (Alonso, 2015; Kotler y Scocco, 2014). Estos trabajos mostraron las variaciones en las experiencias locales, la existencia de temporalidades diferenciadas (los momentos de emergencia y desarrollo de los organismos y la constitución del movimiento defensista), los diversos repertorios de acción o la articulación entre actores sociales y políticos y organizaciones de derechos humanos, evidenciando la incidencia de dinámicas locales específicas que no son una simple reproducción de lo sucedido en el área capitalina.

Por su parte, en su estudio sobre los movimientos vecinales en el conurbano bonaerense en la última etapa de la dictadura -los denominados "vecinazos"-, González Bombal (1998) destacaba la importancia de la dimensión barrial o de los espacios de participación colectiva y de relación con el poder municipal en un contexto de "arrasamiento" de la política como el que se había verificado en aquellos años, situando al ámbito barrial como uno de los lugares de resistencia a las políticas dictatoriales. Las relaciones entre el estado municipal y las asociaciones de vecinos, así como las protestas vecinales y barriales vinculadas con las políticas dictatoriales han sido uno de los temas explorados, no sólo para la provincia de Buenos Aires, sino también para otras ciudades localizadas en las provincias de Santa Fe y Córdoba (Vommaro, 2009; Solis, 2016; Snitcofsky, 2018; Águila, 2019; Tonon, 2020).

\section{LA REPRESIÓN A ESCALA LOCAL}

Desde los años 80 y 90, investigadores e investigadoras de diversas disciplinas sociales se han ocupado del estudio de la última dictadura argentina y, en particular, del ejercicio de la violencia estatal y las violaciones a los derechos humanos cometidas por las Fuerzas Armadas y de seguridad. Si bien el interés sobre la temática no es nuevo, los estudios más recientes han avanzado en la descripción y análisis del ejercicio de la violencia estatal y paraestatal, aportando perspectivas novedosas en una serie de aspectos, entre ellos en las modalidades y dispositivos represivos, en los perpetradores y las víctimas o en las articulaciones entre prácticas legales y clandestinas, en distintas escalas y contextos (Águila, 2019).

Uno de los ejes de esta renovada producción fue la puesta en debate de las temporalidades en el ejercicio de la violencia estatal, señalando las continuidades existentes entre la represión pre y post-golpe y rediscutiendo las periodizaciones establecidas. En esta dirección, se ha inscripto a la última dictadura en una serie de formas de represión de más amplio alcance y de larga duración (Bohoslavsky y Franco, 2020) y, sobre todo, se han ampliado los estudios sobre la violencia paraestatal en los años previos al golpe de estado de 1976. A lo que ya se conocía sobre el período (la actuación de bandas armadas como la Triple A o los inicios de denominada lucha antisubversiva en la provincia de Tucumán), se agregaron investigaciones sobre el proceso de "depuración interna" del peronismo, sobre la actuación de comandos paraestatales o sobre las articulaciones entre las fuerzas represivas y los grupos y organizaciones de la derecha, en algunas provincias y ciudades, ${ }^{3}$ si bien aún no se cuenta con un conocimiento amplio y detallado sobre las formas y características de la violencia estatal y paraestatal en esos años en muchos otros espacios.

En lo que refiere a la represión implementada por las Fuerzas Armadas y de seguridad a partir de 1975-1976, debe señalarse que fue organizada a escala nacional sobre la base de un esquema territorial y con un cierto grado de coordinación entre los comandos cinco Zonas de Defensa en las que se dividió el territorio, pero en términos operativos se implementó en forma descentralizada, no sólo a nivel de las zonas militares, sino también a nivel de las subzonas y áreas. Esta dualidad entre la organización "desde arriba" a escala nacional y la descentralización operativa a escala local y regional, que le otorgó al ejercicio de la represión 
modalidades y características específicas según las distintas áreas, constituye uno de sus rasgos distintivos (Águila, 2013). Con todo y el hecho de ser una de las principales claves para su estudio, todavía existe un conocimiento bastante desigual sobre el ejercicio de la violencia estatal en las distintas provincias y áreas. Por añadidura, tiene orígenes diversos: algunos pocos trabajos de investigación académica, reconstrucciones realizadas por organismos de derechos humanos, testimonios de sobrevivientes, relatos periodísticos o lo investigado en el ámbito judicial, lo que compone un cuadro fragmentario y dispar. En lo que refiere a la investigación académica, las indagaciones se han concentrado, con diferentes énfasis y desarrollos, en algunas agencias y dispositivos represivos y en algunos espacios locales y regionales como Rosario y Santa Fe, Tucumán, Córdoba, Mar del Plata, Bahía Blanca y Norpatagonia. ${ }^{4}$

Para implementar la denominada lucha contra la subversión, las Fuerzas Armadas establecieron una jerarquía de objetivos. Expresados en términos territoriales la prioridad estuvo asignada a algunas zonas y, en particular, se focalizó en los grandes centros urbanos de las provincias más pobladas, calificadas como "zonas calientes” (Tucumán, Capital Federal y La Plata, Córdoba, Rosario y Santa Fe), mientras otras provincias y áreas serían controladas para evitar que se extendiera la "acción subversiva". Esta distinción o jerarquía establecida entre las distintas zonas mostraba que no todas tuvieron la misma centralidad en la estrategia militar, aunque como se ha señalado esto no restringió la utilización en todas ellas de prácticas y dispositivos represivos similares (Scatizza, 2015).

La aplicación de la estrategia represiva tuvo diferentes intensidades según las zonas, así como características y modalidades específicas en los distintos espacios locales y provinciales, vinculados en gran parte a los recursos y opciones disponibles en cada uno de ellos. En primer lugar, la participación de las distintas fuerzas represivas tuvo un carácter diferenciado según el área que se analice. $\mathrm{Ni}$ el involucramiento de las tres armas fue equivalente, ni la participación de la Policía Federal, las policías provinciales o las fuerzas de seguridad como Gendarmería o Prefectura Naval, tuvo la misma modalidad en las distintas áreas. La presencia del Ejército en todo el territorio nacional y su activa intervención en la denominada lucha antisubversiva contrasta con una participación más acotada territorialmente de la Armada (que operó fundamentalmente en la ciudad de Buenos Aires con sede de la ESMA y tuvo activa presencia en Bahía Blanca o Mar del Plata, donde existían bases navales) y la Aeronáutica (que organizó algunos circuitos represivos, como el que tenía base en el partido de Morón o participó activamente en otras, por ejemplo en la zona norte de la provincia de Santa Fe).

La unidad militar al mando dentro de cada subdivisión territorial tenía bajo su control operacional a un conjunto de fuerzas policiales y de seguridad, con una composición y una participación distinta según cada jurisdicción. Por ejemplo, en el caso de Gendarmería se ha probado su participación en muchos de los centros clandestinos de detención como responsables de la seguridad de estos lugares, si bien en las provincias fronterizas sus miembros tuvieron una participación más activa y destacada en el ejercicio de la represión. Por su parte, en algunas áreas el accionar de la policía provincial parece haber ostentado una mayor autonomía en la planificación y ejecución de las acciones represivas, con todo y encontrarse bajo control operativo de las distintas zonas militares y cuerpos de Ejército, en algunas áreas respecto de otras, como he estudiado para el caso de la policía de Rosario (Águila, 2008a). Finalmente, existen evidencias de disputas producidas entre la policía y las Fuerzas Armadas respecto del ejercicio del accionar represivo, vinculadas con la decisión de algunos comandantes de cuerpo de centralizar dichas acciones y desplazar a la policía provincial (a quienes responsabilizaban del accionar de las "patotas") o reducir su autonomía.

Los comandantes de las zonas de defensa tuvieron amplias prerrogativas para organizar, conducir e implementar la represión en sus respectivas jurisdicciones, resultado de la estrategia de "ejecución descentralizada”. Esto se reflejó en la estructuración de distintos circuitos represivos a nivel de zonas, subzonas y áreas, cuyas características y modalidades de funcionamiento fueron variadas, dependiendo del área geográfica sobre la que se actuaba, la población sobre la que se ejercía la vigilancia y se implementaba la estrategia represiva, la complejidad de dicha estructura (cantidad de grupos operativos, centros clandestinos, 
intervención de las diversas fuerzas) y los recursos disponibles para desaparecer los cadáveres. Ello no excluyó que los prisioneros pudieran ser trasladados a otros centros (tuvieran o no vinculación entre sí) o que las distintas fuerzas represivas operaran articuladas en la ejecución de determinadas acciones que implicaran por ejemplo traspasar las "fronteras" de las respectivas áreas, aunque la evidencia disponible muestra una lógica de actuación localizada de los grupos operativos, incluso en áreas vecinas territorialmente, que debe ser considerada.

Como se advierte, en lo que refiere al ejercicio de la represión la mirada situada en lo local resulta clave, sin la cual muchos de sus elementos constitutivos resultan ocluidos o velados. Más allá del diseño y organización de la represión, ciertas lógicas y rasgos que la caracterizaron adquieren otra dimensión cuando focalizamos el análisis en espacios más acotados, en tanto la planificación de la estrategia represiva -de alcances nacionales- se implementó en ámbitos locales o regionales específicos: los "grupos de tareas" actuaron en circuitos represivos que tenían una lógica regional o local definida (zonas, subzonas, áreas), estaban constituidos por individuos que se reclutaron en general en dichos ámbitos, los centros clandestinos de detención estaban localizados en centros urbanos y/o sus zonas vecinas, la represión se dirigió hacia estructuras militantes de actuación local, regional o provincial, sólo para reseñar algunas de sus características.

En mi investigación sobre el ejercicio de la represión en Rosario y su área de influencia he estudiado la constitución de los grupos de perpetradores, integrados por hombres que revistaban en las distintas fuerzas policiales o militares que actuaban en la ciudad o con civiles que se incorporaron a ellos, un número importante de los cuales eran oriundos y/o vivían en este ámbito local o regional (Águila, 2018). El accionar represivo se nutrió en forma muy significativa del conocimiento bastante exhaustivo que poseían de algunas de sus víctimas y sobre todo de ciertas redes que se habían articulado previamente y se utilizaron para desmantelar las estructuras militantes. En tal sentido, el ejercicio de la represión estatal no puede ser escindido de un entramado de relaciones y articulaciones sociales y políticas que se significan sólo cuando la escala del análisis se recorta a un marco local o regional.

\section{LOS ARCHIVOS PARA EL ESTUDIO DEL PASADO RECIENTE EN CLAVE LOCAL}

Como planteaba al inicio, la elección de una escala de observación y análisis local fue, en parte, condicionada o determinada por la disponibilidad y/o el mayor acceso a archivos y fondos públicos o privados, provinciales o locales, que conforman la base de la mayor parte de las investigaciones sobre la dictadura y la represión. Se trata de diversos reservorios estatales provinciales o municipales, los denominados "archivos de la represión" y/o archivos de la memoria que existen en varias provincias y ciudades del país, que contienen fondos de inteligencia, así como archivos castrenses, archivos hemerográficos, fondos documentales de organizaciones intermedias o movimientos sociales, archivos privados, entre otros, que se suman a los archivos orales y los testimonios orales, que siguen constituyendo una de las fuentes más utilizadas por los investigadores del pasado reciente argentino.

Ciertos reservorios son ya casi una fuente "natural" para la investigación sobre lo local, señaladamente la prensa producida y editada localmente. A diferencia de los medios nacionales, la misma reseñaba los acontecimientos que se verificaban en esos espacios locales y regionales, en tanto la cobertura periodística ostentaba (y ostenta aún) una dimensión fuertemente local y regional que no reflejaban los diarios editados la Capital Federal o incluso las capitales de provincia. Muchos de estos medios de prensa desempeñaron adicionalmente un rol muy importante en la configuración de la opinión pública local: la prensa fue el vehículo -junto con la radio y la televisión - a través del cual la población se informaba, el ámbito donde se difundían los problemas y temas locales y provinciales, donde se cubrían ciertos eventos y se transcribían declaraciones de los funcionarios estatales y de los sectores que hacían públicos sus posicionamientos, donde se reflejaba la conflictividad laboral y social, donde se reseñaban los resultados de la "acción antisubversiva" ejecutada por las fuerzas del orden, en fin, donde un conjunto significativo de acontecimientos se informaban 
o se editorializaban. Esa sucesión de hechos y procesos, el impacto local de algunos temas y cuestiones que jalonaron el período, la reconstrucción de los climas políticos y sociales, serían muy difíciles de reconstruir sin recurrir a la prensa como fuente.

Por otro lado, contamos con fondos de diversas agencias estatales (nacionales, provinciales y municipales), que muestran una cuestión planteada insistentemente: que el estado registra sus acciones, incluso aquellas que se encuentran por fuera de la legalidad. Además de los archivos de distintas burocracias estatales (ministeriales, de ámbitos provinciales y municipales, archivos judiciales, archivos universitarios), usualmente de acceso público y en general poco explorados para el estudio del pasado reciente, la novedad más impactante en términos de la investigación académica han sido archivos de agencias represivas, castrenses, policiales y/o de organismos de inteligencia.

Los denominados genéricamente "archivos de la represión" y/o los archivos de la memoria localizados en varias provincias y ciudades, son repositorios que contienen documentos de diversa índole vinculados con la vigilancia, control y/o persecución de hombres y mujeres realizada por las fuerzas de seguridad o, más en general, que incluyen datos sobre el accionar de las fuerzas represivas o sobre violaciones a los derechos humanos cometidas en aquellos años. El archivo DIPBA, el Archivo Provincial de la Memoria de Santa Fe, el Archivo Provincial de Córdoba, el Archivo Nacional de la Memoria, contienen fondos o series documentales producidas por agencias de inteligencia (policiales, militares, gubernamentales) y, en lo que refiere a los estudios locales sobre la dictadura y la represión, han impulsado la investigación en varias direcciones: permitiendo reconstruir el funcionamiento de algunas de esas agencias, que en general integraban tramas represivas que operaban en zonas, subzonas y áreas locales específicas, vigilaban y perseguían a individuos, grupos y organizaciones que tenían militancia, activaban o simplemente vivían, trabajaban o estudiaban en espacios locales, y como primera función, recogían y producían información a través de distintas vías y la circulaban en comunidades informativas que también solían estructurarse por zona, subzona o área (es decir, a escala local, provincial, regional). Adicionalmente, estos archivos han mostrado su valor para el estudio de organizaciones políticas, sociales, sindicales o culturales, algunas de las cuales actuaban localmente, sobre las que estas agencias recopilaban información y producían informes de inteligencia para su vigilancia y control y, eventualmente, para el despliegue represivo. Por su parte, y sin que esto signifique cerrar las posibilidades que presentan para la investigación, estos fondos documentales dan cuenta no sólo de la represión física sino de estrategias de disciplinamiento y control implementadas por el estado hacia individuos, sectores y organizaciones, tanto como registran actitudes de grupos, organizaciones políticas, asociaciones civiles, sindicatos, movimientos sociales, etc., contribuyendo a la indagación sobre los comportamientos sociales en contextos represivos, también a escala local.

A ello hay que agregarle la apertura de los archivos del Ejército y las demás Fuerzas Armadas, impulsada por las políticas de memoria por parte del estado y el aporte de datos y documentación a las causas judiciales por delitos de lesa humanidad, que contribuyó a la recuperación y puesta a disposición de material documental que les pertenecía. El acceso amplio a fondos documentales de las Fuerzas Armadas, en particular del Ejército, ha impulsado la indagación sobre la institución militar, los marcos normativos y reglamentarios, los procedimientos represivos, etc. Se cuenta también con unos pocos estudios sobre la Armada, el Servicio Penitenciario Federal y algunos establecimientos carcelarios de alta seguridad y, en menor medida aún, sobre el accionar de las policías en el período de mayor intensidad represiva.

Como ejemplo, y como hemos observado en nuestra investigación sobre el Comando del $\mathrm{II}^{\circ} \mathrm{Cuerpo}$ de Ejército con sede en Rosario (Águila et al., 2017), ha sido de enorme valor la documentación contenida en el Servicio Histórico del Ejército, en particular sus Libros Históricos (confeccionados anualmente de forma obligatoria por cada unidad y/o gran unidad militar, que se elevaban al Comando en Jefe del Ejército), que brindan información sobre la orgánica de la unidad, personal, y resumen de las principales actividades desarrolladas en el año (actos, conmemoraciones, cambio de mandos, inspecciones, etc.); legajos del personal militar, producidos por la institución a los fines de registrar la carrera militar de cada uno de los agentes desde 
su ingreso a las academias hasta su fallecimiento, y los reglamentos militares, un conjunto de disposiciones orgánicas que regulan diferentes aspectos y cuestiones relacionadas con la doctrina militar y las prácticas y orientan el accionar de la fuerza, y que brindan referencias sobre la organización del despliegue represivo en áreas, zonas y subzonas. Los trabajos disponibles sobre la Armada en algunas ciudades atlánticas (como Mar del Plata y Bahía Blanca) y para el Ejército en la provincia de Buenos Aires, Tucumán y en la Norpatagonia, han hecho uso de fuentes y reservorios documentales similares a los mencionados (Iturralde y Barragán, 2019; Montero, 2016 y 2019; Garaño, 2016 y 2020; Scatizza, 2016).

El otro corpus que se ha revelado como fundamental para el estudio de las dinámicas represivas es la documentación recopilada en las distintas causas judiciales por delitos de lesa humanidad que se sustanciaron en casi todas las provincias del país y que han reconstruido específicos circuitos represivos que operaban a escala provincial, local y regional. En el caso de las fuentes judiciales -tanto sean contemporáneas a los hechos, como sucede con las tramitadas por presentación de hábeas corpus, por privación ilegítima de la libertad, por hallazgo de cadáveres o las que se siguieron en la justicia militar por represión a las acciones "antisubversivas", como las posteriores a esos acontecimientos, incoadas para investigar y juzgar delitos de lesa humanidad-su valor como repositorios documentales para la investigación sobre el problema es riquísima, ya que contienen un caudal heterogéneo y muy significativo de información: denuncias recogidas a principios de los años' 80 por organismos de derechos humanos que actuaban a nivel provincial o local o por CONADEP, testimonios de las víctimas y/o de testigos de hechos represivos perpetrados en contextos situados, así como declaraciones de los miembros de las fuerzas de seguridad involucrados en las causas (Feld y Salvi, 2019), junto con documentos de diversa naturaleza procedentes de los servicios de informaciones policiales y militares, que configuraron la evidencia documental de los hechos denunciados o investigados perpetrados en específicos circuitos represivos.

Finalmente, podríamos listar otro conjunto de registros confeccionados por asociaciones u organizaciones empresariales, sindicales, eclesiásticas o archivos del movimiento de derechos humanos, que permiten explorar la sociabilidad, los comportamientos sociales o la conflictividad a escala "micro"; las colecciones documentales y hemerográficas, muchas prácticamente inhallables hasta hace pocos años, que se encuentran en sitios web de acceso abierto; los documentos y archivos de carácter privado, con accesibilidad variable y diferenciada; todos los que vienen mostrado sus potencialidades y relevancia para las investigaciones y estudios a escala local.

\section{A MODO DE CIERRE}

Si la dictadura militar y el ejercicio de la represión son, indudablemente, procesos y problemas de alcance y envergadura nacional, ¿ por qué insistir o sostener la necesidad de una mirada desde lo local? Para empezar, porque la interrogación y la indagación desde ese punto de mira permite o habilita la detección y el estudio de dimensiones que frecuentemente no se registran desde una perspectiva general. La reducción de la escala puede contribuir a mostrar variaciones, aristas o componentes del objeto o proceso estudiado, que la historia "nacional" o el macro-análisis no necesariamente incluyen o contemplan, como he tratado de reseñar para las investigaciones sobre el régimen militar y el ejercicio de la represión estatal y paraestatal.

Aunque todo esto justificaría ampliamente la elección de la escala, creo que no es suficiente. A mi juicio, la opción por lo local tiene cabal sentido y utilidad para la producción y el avance del conocimiento histórico si se convierte en una "ventana" para explicar y comprender un problema de dimensiones más vastas. No se trata de postular la necesidad de acumular estudios empíricos, análisis de caso o historias locales para converger en la construcción de una historia nacional a la postre omnicomprensiva y generalizadora, sino por el contrario, de aspirar a que la mirada desde lo particular, lo micro o lo local ilumine, complejice y contribuya a la explicación y la comprensión del proceso en su singularidad tanto como de lo general, lo nacional, lo global. 


\section{ReFERENCIAS}

Águila, G. (2008) Dictadura, represión y sociedad en Rosario. Un estudio sobre la represión y los comportamientos y actitudes sociales en dictadura. Buenos Aires: Prometeo.

Águila, G. (2013) La represión en la Argentina: modalidades, dinámicas regionales y efectos sociales. En G. Águila y L. Alonso (comps.) Procesos represivos y actitudes sociales: entre la España franquista y las dictaduras del Cono Sur. Buenos Aires: Prometeo.

Águila, G. (2014) Disciplinamiento, control social y 'acción sicológica' en la dictadura argentina. Una mirada a escala local: Rosario, 1976-1981. Revista Binacional Brasil-Argentina, 3(1), 211-239. Recuperado de: https://periodi cos2.uesb.br/index.php/rbba/article/view/1392

Águila, G. (2018) Los perpetradores de la represión en la Argentina durante los años 1970: problemas y perspectivas de análisis a través de un estudio de caso. En Cordeiro, J. et al. (orgs.) Violência politica no século XX. Pernambuco: EDUPE.

Águila, G. (2019) El régimen militar entre la represión y el consenso intendencia del capitán Cristiani y las asociaciones vecinales, Rosario 1976-1981. Anuario IEHS 34(1). Recuperado de: http://anuarioiehs.unicen.edu.ar/Files/20 19\%201/06\%20Anuario\%20IEHS\%2034(1)\%20d.Aguila.pdf

Águila, G. (dir.) et al. (2017) Territorio ocupado. La historia del Comando del II Cuerpo de Ejército en Rosario (1960-1990). Rosario: Editorial Municipal de Rosario/Museo de la Memoria.

Águila, G., Garaño, S. y Scatizza, P. (coords.) (2016) Represión estatal y violencia paraestatal en la historia argentina reciente. Nuevos abordajes a 40 años del golpe de estado. La Plata: FaHCE. Recuperado de: https://www.libros.f ahce.unlp.edu.ar/index.php/libros/catalog/book/63

Águila, G., Garaño, S. y Scatizza, P. (coords.) (2020) La represión como politica de Estado. Estudios sobre la violencia estatal en el siglo XX. Buenos Aires: Imago Mundi.

Alonso, L. (2015) Redes y dimensiones espaciales en la movilización por los derechos humanos en Argentina. Avances del Cesor, 12(12), 117-139. https://doi.org/10.35305/ac.v12i12.432

Alonso, L. (2016) Sobre la vida (y a veces la muerte) en una ciudad provinciana. Terror de Estado, cultura represiva y resistencias en Santa Fe. En G. Águila, Garaño, S. y Scatizza, P. (coords.) Represión estatal y violencia paraestatal en la historia reciente argentina (423-450), cit.

Ballester, G. (2016a) Las dirigencias del asociacionismo en la historia reciente argentina: el caso de General Sarmiento, 1973-1983. Tesis de Maestría en Historia Contemporánea, Universidad Nacional de General Sarmiento.

Ballester, G. (2016b) Sociabilidad y poder local: los Bomberos Voluntarios de General Sarmiento (1945-1983). Páginas, 8(17), 26-45. https://doi.org/10.35305/rp.v8i17.223

Barragán, I. y Iturralde, M. (2019) La estructura represiva de la Armada Argentina desde una perspectiva regional. Apuntes y consideraciones sobre la Fuerza de Tareas 6 durante la última dictadura militar en Argentina. Historia Regional, (41), 1-13. Recuperado de: http://historiaregional.org/ojs/index.php/historiaregional/index

Besoky, J. L. (2016) Violencia paraestatal y organizaciones de derecha. Aportes para repensar el entramado represivo en la Argentina, 1970-1976. Nuevo Mundo Mundos Nuevos. Recuperado de: http://nuevomundo.revues.org/6 8974

Bohoslavsky, E. y Franco, M. (2020) Elementos para una historia de las violencias estatales en la Argentina en el siglo XX. Boletín del Instituto Ravignani, (53), 119-123. https://doi.org/10.34096/bol.rav.n53.8009

Bohoslavsky, E. y Lvovich, D. (2017) La historia reciente argentina a escala regional (1973-1983). En S. Bandieri y S. Fernández (eds.) La historia nacional en perspectiva regional, tomo II (215-238). Buenos Aires: Teseo.

Canelo, P. (2011) Construyendo elites dirigentes. Los gobernadores provinciales durante la última dictadura militar (Argentina, 1976-1983). Anuario del Centro de Estudios Históricos "Prof. Carlos S. A. Segreti", 11(11), 323-341. Recuperado de: https://revistas.unc.edu.ar/index.php/anuarioceh/article/view/23034

Canelo, P. (2015) La importancia del nivel municipal para la última dictadura militar argentina: un estudio a través de sus documentos reservados y secretos (1976-1983). Historia (Santiago), 48(2), 405-434. https://dx.doi.org/ $10.4067 /$ S0717-71942015000200001 
Citroni, J. (2011) Modos de control del espacio urbano en un contexto de poder autoritario. El caso de Santa Fe, Argentina, 1976-1981. Urbano, 14(24), 69-80. Recuperado de: http://revistas.ubiobio.cl/index.php/RU/artic le/view/271.

Correa Morales, J. (2016) Las Juntas de Vecinos: "una forma patriótica y desinteresada de participación ciudadana". Análisis centrado en la ciudad de Durazno, 1973-1980. Claves. Revista De Historia, 2(2), 227-256. https://do i.org/10.25032/crh.v2i2.9

Demasi, C. (2013) Las ambiguas formas de coexistencia. La sociedad uruguaya frente a la dictadura. En G. Águila y L. Alonso (coords.) Procesos represivos y actitudes sociales (197-220), cit.

Di Giorgi, G. (2014-2015) En los pliegues de la planificación del Onganiato: el comunitarismo como política estatal (1966-1970). Anuario IEHS, (29-30), 159-175. Recuperado de: http://anuarioiehs.unicen.edu.ar/Files/201415/09\%20Anuario\%20IEHS\%2029\&30.D1.Giorgi.pdf

Feld, C. y Salvi, V. (eds.) (2019) Las voces de la represión. Declaraciones de perpetradores de la dictadura argentina. Buenos Aires: Miño y Dávila.

Franco, M. y Lvovich, D. (2017) Historia Reciente: apuntes sobre un campo de investigación en expansión. Boletín del Instituto Ravignani, (47) 190-217. Recuperado de: https://ppct.caicyt.gov.ar/index.php/ravignani/article/ view/11091/pdf_1\#

Galván, V. y Osuna, F. (2014) Politica y cultura durante el Onganiato. Nuevas perspectivas para la investigación de la presidencia de Juan Carlos Onganía (1966-1970). Rosario: Prohistoria.

Garaño, S. (2021) Ensayo del terrorismo de Estado en Argentina: el Operativo Independencia (Tucumán, 1975-1977). Boletin del Instituto Ravignani, (54), 137-162. https://doi.org/10.34096/bol.rav.n54.9533

González Bombal, I. (1988) Los vecinazos. Las protestas barriales en el Gran Buenos Aires, 1982-83. Buenos Aires: IDES.

Jensen, S. (2010) Diálogos entre la historia local y la historia reciente en la Argentina. Bahía Blanca durante la última dictadura militar. En E. Rey Tristán y P. Calvo González (comps.) 200 años de Iberoamérica (1810-2010). Actas del XIV Encuentro de Latinoamericanistas Españoles. Universidad de Santiago de Compostela.

Jensen, S. y Lastra, S. (2015) El problema de las escalas en el campo de estudio de los exilios políticos argentinos recientes. Avances del Cesor, 12(12), 97-115. https://doi.org/10.35305/ac.v12i12.431

Kotler, R. y Scocco, M. (2014) Estudio introductorio: los orígenes del movimiento de derechos humanos en la periferia argentina. Un mapa por trazar. En R. Kotler (comp.) En el pais del si me acuerdo. Los origenes nacionales e internacionales del movimiento de derechos humanos argentino, Buenos Aires: Imago Mundi.

Ladeuix, J. (2012) Los últimos soldados de Perón: reflexiones en torno a la violencia paraestatal y la derecha peronista a través de una experiencia local. 1973-1976. En Bohoslavsky, E. y Echeverría, O. (comps) Las Derechas en el Conos Sur, Siglo XX. Actas del Segundo Taller de Discusión. Tandil: FCH-IEHS/UNICEN. Recuperado de: ht tps://www.ungs.edu.ar/idh/derechas/

Lvovich, D. (2010) Burócratas, amigos, ideólogos y vecinalistas: el reclutamiento de funcionarios municipales de Morón durante la Dictadura Militar (1976-1983). En E. Bohoslavsky y G. Soprano (eds.) Un Estado con rostro humano. Funcionarios e instituciones estatales en Argentina (desde 1880 a la actualidad) (411-430). Buenos Aires: UNGS-Prometeo.

Margaria, P. y Schnyder, C. (2017) La política bajo sospecha. Regularidades y reformulaciones de la vigilancia política en Argentina: la policía de Santiago del Estero. Nuevo Mundo Mundos Nuevos. Recuperado de: http://journals .openedition.org/nuevomundo/68129?lang=pt.

Máspoli, E. (2013). La legitimación del 'Proceso de Reorganización Nacional' en el ámbito local. Actores y estrategias discursivas en torno a la Primera Exposición Internacional de la Producción, la Industria y el Comercio. Junín, 1977. Mundo Agrario (14)27. Recuperado de: en: http://www.memoria.fahce.unlp.edu.ar/art_revistas/pr.594 8/pr.5948.pdf.

Merele, H. (2017) La depuración ideológica del peronismo en General Sarmiento (1973-1974). La Plata y Los Polvorines: UNLP, UNGS y UNaM. Recuperado de: https://www.libros.fahce.unlp.edu.ar/index.php/libros/catalog/boo $\mathrm{k} / 88$ 
Montero, M.L. (2019) Violencia política y disciplinamiento social durante la última dictadura militar argentina. Modalidades represivas en Bahía Blanca, Argentina (1976-1977). HiSTOReLo, 11(21). http://dx.doi.org/10.1 5446/historelo.v11n21.69327

Moreno, A.(2020) Orden y moral: el coronel Romanutti en la intendencia de Córdoba (1976-1979). En C. Tcach (comp.) Los intendentes de Córdoba en el siglo XX: liderazgos, gestiones y relaciones entre nación, provincia y municipio. Córdoba: Editorial de la UNC.

Nemec, D. (2019) Pueblos de la guerra. Pueblos de la paz. Tucumán: EDUNT.

Paiaro, M. (2016) Exhibir el terror. El Comando Libertadores de América: Entre el asesinato político y la restauración de la honra. En A. C. Solis y P. Ponza (comps.) Córdoba a 40 años del Golpe: estudios de la dictadura en clave local (105-122). Córdoba: UNC. Recuperado de: https://ffyh.unc.edu.ar/editorial/wp-content/uploads/sites/5/20 13/05/EBOOK_40A\%C3\%91OSGOLPE.pdf

Pittaluga, R. (2017) Ideas (preliminares) sobre la historia reciente. Ayer. Revista de Historia Contemporánea, (107), 21-45. Recuperado de: https://revistaayer.com/articulo/161

Ponisio, M. (2016) La capilaridad del gobierno militar durante la última dictadura (1976-1983). Un abordaje de caso desde el nivel de las agencias estatales comunales de la provincia de Santa Fe. Historia Regional, (35), 7-18. Recuperado de: https://ri.conicet.gov.ar/handle/11336/62017

Pons, A. y Serna, J. (2007) Más cerca, más denso: la historia local y sus metáforas. En S. Fernández (comp.) Más allá del territorio. La historia regional y local como problema (17-30). Rosario: Prohistoria.

Quiroga, H. (1994) El tiempo del "Proceso". Conflictos y coincidencias entre politicos y militares. 1976-1983. Rosario: Ed. Fundación Ross.

Rodríguez Agüero, L. (2009) Mujeres en situación de prostitución como blanco del accionar represivo: el caso del Comando Moralizador Pío XII, Mendoza, 1974-1976. En A. Andújar et al. (comps.) De minifaldas, militancias y revoluciones. Exploraciones sobre los 70 en Argentina. Buenos Aires: Luxemburg.

Rodríguez, L. G. (2009) Descentralización municipal, intendentes y 'fuerzas vivas' durante el Proceso (1976-1983). Cuestiones de Sociologia, (5-6), 369-387. Recuperado de: http://www.memoria.fahce.unlp.edu.ar/art_revistas/p r.4065/pr.4065.pdf

Scatizza, P. (2015) Un Comahue no tan frío: La Norpatagonia argentina en el proyecto represivo de la dictadura militar (1975-1983). Izquierdas, (23), 66-80. https://dx.doi.org/10.4067/S0718-50492015000200004

Scatizza, P. (2016) Represión 'antisubversiva' en la Norpatagonia. Estrategias estatales y paraestatales de persecución política en Neuquén y Río Negro (1973-1976). Papeles de Trabajo, 10(17), 52-72. Recuperado de: http://revis tasacademicas.unsam.edu.ar/index.php/papdetrab/article/view/70

Schneider, A. y Simonassi, S. (2019) Debates y perspectivas en torno a la historia reciente de los trabajadores en Argentina. En G. Águila et al. (coords.) La historia reciente en Argentina. Balances de una historiografia pionera en América Latina. Buenos Aires: Imago Mundi.

Snitcofsky, V. (2018) La erradicación de villas en la ciudad de Buenos Aires: características específicas y contexto general (1976-1983). Clepsidra, 5(10), 54-75. Recuperado de: https://ppct.caicyt.gov.ar/index.php/clepsidra/a rticle/view/Snitcofsky/pdf

Solis, A. C. (2016) La última dictadura y los barrios de la ciudad de Córdoba. Aproximación a las protestas de vecinos y a las intervenciones estatales hacia un vecinalismo permitido. Revista de Historia, (17), 175-201. Recuperado de: http://revele.uncoma.edu.ar/htdoc/revele/index.php/historia/article/view/1338/pdf

Tonon, M. C. (2021) Protestas vecinales durante la transición democrática argentina. Estudio sobre su desarrollo en un municipio de la provincia de Santa Fe (1982). En J. Larker y M. C. Tonon (comps.) Orden y conflictividad social entre los siglos XIX y XXI: miradas espacializadas en territorio santafesino. Buenos Aires: Teseo.

Valdivia Ortiz de Zárate, V., Álvarez Vallejos, R. y Donoso Fritz, K. (2012) La alcaldización de la política. Los municipios en la dictadura pinochetista. Santiago: LOM.

Vommaro, P. (2009) Territorios, organizaciones sociales y migraciones: las experiencias de las tomas de tierras y los asentamientos de 1981 en Quilmes. Espaço Plural, (20), 81-93. Recuperado de: https://www.redalyc.org/pdf/ 4459/445944362010.pdf 
Yannuzzi, M. A. (1996) Politica y Dictadura. Rosario: Ed. Fundación Ross.

Zapata, A. B. (2012) Violencia parapolicial en Bahía Blanca, 1974-1976. Delgados límites entre lo institucional y lo ilegal en la lucha contra la subversión apátrida. Anos 90, (35). Recuperado de: http://seer.ufrgs.br/anos90/arti cle/viewFile/29141/24257

\section{Notas}

* Gabriela Águila es autora de Dictadura, represión y sociedad en Rosario (2008), coeditora de Procesos represivos y actitudes sociales: entre la España franquista y las dictaduras del Cono Sur (2013), Represión estatal y violencia paraestatal en la historia reciente argentina (2016) y La represión como politica de Estado. Estudios sobre la violencia estatal en el siglo XX (2020) y directora de Territorio ocupado. La historia del Comando del II Cuerpo de Ejército en Rosario (2017).

1 "Una escala es una categoría que se adopta con la finalidad de aprehender una realidad y lograr representarla. En otras palabras, el historiador al optar por una escala está tomando una decisión explícita respecto a la cantidad y al tipo de información que considera adecuada para alcanzar su propósito. En consecuencia no existe una relación lineal entre lo que el historiador se propone estudiar y las modalidades más apropiadas que tiene para representarlo" (Pons y Serna, 2007:25).

2 Al respecto véase Lvovich, 2010; Águila, 2008, 2014 y 2019; Citroni, 2011; Máspoli, 2013; Alonso, 2016; Ballester, 2016a y 2016b; Solis, 2016; Ponisio, 2016; Montero, 2019; Tonon, 2020. Para el reclutamiento de funcionarios, los estudios de Rodríguez, 2009; Canelo, 2011 y 2015.

3 Las provincias más estudiadas han sido Buenos Aires (fundamentalmente las ciudades de La Plata, Mar del Plata, Bahía Blanca o el norte del conurbano bonaerense), Córdoba, Santa Fe, Mendoza, Tucumán y Norpatagonia Véanse, entre otros, los trabajos de Rodríguez Agüero, 2009; Ladeuix, 2012; Zapata, 2012; Merele, 2015; Besoky, 2016; Paiaro, 2016; Scatizza, 2016; Garaño, 2020.

$4 \mathrm{Al}$ respecto ver algunos de los artículos contenidos en los volúmenes colectivos coordinados por Águila, Garaño y Scatizza, 2016 y 2020; Águila et al., 2017. También el balance historiográfico en Águila, 2019 y, entre otros, los trabajos de Nemec, 2019; Barragán e Iturralde, 2019; Margaria y Schynder, 2017. 